Volume 9, No.1.4, 2020

International Journal of Advanced Trends in Computer Science and Engineering

Available Online at http://www.warse.org/IJATCSE/static/pdf/file/ijatcse5091.42020.pdf

https://doi.org/10.30534/ijatcse/2020/5091.42020

\title{
On The Challenges and Performance Evaluation of Femtocell in Ultra Dense Network
}

\author{
N. Mohd Nordin ${ }^{1}$, A.S. Ab Ghafar ${ }^{2}$, F.A. Saparudin ${ }^{3}$, N.N Hairul Rozi ${ }^{4}$ \\ ${ }^{1}$ Department of Electrical Engineering Technology, Faculty of Engineering Technology, Universiti Tun Hussein \\ Onn Malaysia, Malaysia, akmalianordin@gmail.com \\ ${ }^{2}$ Department of Electrical Engineering Technology, Faculty of Engineering Technology, Universiti Tun Hussein \\ Onn Malaysia, Malaysia, aimi@uthm.edu.my \\ ${ }^{3}$ Department of Electrical Engineering Technology, Faculty of Engineering Technology, Universiti Tun Hussein \\ Onn Malaysia, Malaysia, faizs@uthm.edu.my \\ ${ }^{4}$ Department of Electrical Engineering Technology, Faculty of Engineering Technology, Universiti Tun Hussein \\ Onn Malaysia, Malaysia, nadiahhairul@gmail.com
}

\begin{abstract}
Massive development of mobile data traffic in recent years has been predicted to progress in the near future. Moreover, users will await in upcoming wireless network with enormous data rates, less packet drop rates and lower latency. Ultra Dense Network (UDN) is the key technology to meet immensely dense traffic and the future evolution of the fifth generation (5G) mobile communication. Hypothetical download speeds to support $5 \mathrm{G}$ is predicted around 10Gbps with a latency less than $1 \mathrm{~ms}$ contrast with $4 \mathrm{G}$ where the download speed is $1 \mathrm{Gbps}$ [1]. Next, development of $5 \mathrm{G}$ is not just for upgrading of $4 \mathrm{G}$ cell system, but it is an addition of framework with various new policy capacity [2]. Femtocell is one of the high dense cells which is a small cell that can increase capacity and indoor cellular coverage. However, UDN will meet great challenges due to interference, mobility, various quality of service (QoS) demand, spectrum scarcity and energy efficiency. In this paper, challenges of UDN with existence of femtocells are presented. Simulation is done using Network Simulation and Emulation Software (NetSim) in order to study the throughput for various application types of scheduling services. It is shown that delay and throughput are affected by priority level of the applications. Based on the results, constant bit rate (CBR) application has the highest throughput due to high priority in QoS networks. While, QoS of Unsolicited Grant Service (UGS) has highest delay for all applications except for video and voice applications compared to other scheduling services because QoS of UGS prioritizes video and voice applications compared to other applications. Next, the network performance with increasing number of user equipment (UE) is tested when more Home Node B (HNB) are added with their own UEs. This simulation shows that with the additional UEs, the throughput of each UE is decreased due to spectrum resource sharing.
\end{abstract}

Key words : 5G, femtocell, frequency sharing, NetSim, ultra dense network.

\section{INTRODUCTION}

Research towards $5 \mathrm{G}$ wireless communication network is continuous on many fields due to the increased of capacity demands for high data rate services [3]. In order to meet the increased growing demand for wireless data services, wireless networks need to improve network capacity by more than 1000 times beyond 2020 [4]. The small base station will possibly increase the efficiency of frequency reuse and frequency sharing to solve the issues of wireless communication network coverage and power [5]. UDN development will be the cornerstone to 5G's potential growth. In UDN, small cell base stations (SBSs) with low power are installed to improve network spectrum capacity and energy output [6].

Currently, the Third Generation Partnership Project (3GPP) members are establishing 5G requirements. 3GPP members meet regularly to discuss and set standards for cellular communication. The International Telecommunication Union (ITU) has set out several $5 \mathrm{G}$ criteria that concentrate on achieving three main performance indicators (KPIs) which are data maximum speeds above $10 \mathrm{~Gb} / \mathrm{s}$ for enhanced mobile broadband (eMBB), more than 1 MMTC connections, and less than $1 \mathrm{~ms}$ latency for ultra-reliable low-latency communications (URLLC). 3GPP has a specified release schedule to assure that the usual release rate between $4 \mathrm{G}$ and $5 \mathrm{G}$ is maintained and that the specification is completed on time. Release 15 concluded in the plenary session of the Radio Access Network (RAN) in June 2018. A late drop is expected in December 2018 to explore dual communication (DC) with Existing Radio to Existing Radio (NR-NR).

High density cells like femtocell are the small cells that can improve the efficiency of the call and the indoor cellular coverage. The femtocell is a minimal-power, minimal-cost data access point for indoor users with a range of tens of 
meters. A femto base station (FBS) that would connect through a current broadband connection to the provider's network can provide access points for femtocell user equipment (FUEs) [7]. Serious problems with interference occur because femtocells use the same frequency tools as macrocells and typical applications [8]. The implementation of an effective interference management technique is important for promoting the large-scale deployment of femtocells. There are many types of functional schemes studied for interference management [9]-[13]. In [11] [12], the authors focused on supporting network capacity on frequency sharing algorithms in femtocell network. Work on the co-tier femtocell interference challenges was conducted at [14][15].

This paper focuses on the problems of UDN with existence of femtocells. Some of the situation for different UDN challenges is simulated to observe the performance of femtocell towards UDN. Firstly, the throughput for various application types of scheduling services are studied. Then, the performance increasing of number UE is tested with more UEs with newly added HNB.

\section{CHALLENGES IN UDN}

UDN can be described as small cell deployment in dense urban environments where the density of points of access is greater than user density. The active user density observed in a dense urban area is approximately 600 active users / km2 [16]-[18]. The inter site distance (ISD) for fourth generation (4G) deployment is $400 \mathrm{~m}$ distance while for UDN is estimated to decrease by about $100 \mathrm{~m}$ [19]. UDN implementation can face some difficulties and challenges. This is due to the growing density of traffic in areas such as shopping malls and enterprise building that needs both indoor and outdoor deployment to provide maximum coverage and efficiency. The main challenges in UDN are interference, mobility and cost but there are other influence factors. The challenges are discussed in this section.

\subsection{Energy Efficiency}

With the increasing number of traffic demands in UDN, the energy consumption generates severe challenges. Therefore, the problems of energy efficiency have gained significant attention from both academia and industry [20]-[22]. Base station is the most energy consuming which utilizes about $60 \%-80 \%$ of energy use [23]. The energy usage includes both the signal transmission power consumption and equipment energy consumption. However, not all base stations (BSs) are being used evenly in small cell network; some BSs might be fully utilized while others are not, which leads to the energy waste. It can help to reduce energy consumption by turning in powered-on and powered-off mode for BSs. In [24], the algorithm of sustainable power reductions is suggested for the cellular networks. They proposed that the BSs alternate to lower their power by considering the existing power settings of their neighbors. Furthermore, energy from wind, sunlight and environmental vibration sources will deliver energy harvest without pollution [25].

\subsection{Interference Management}

Interference management is an important issue and challenge in UDN. Due to the large number of neighboring cells, interference management might be challenging to overcome this issue. In addition, the decreased distance in UDN between both the transmitter and the receiver increases the interference due to the direction of the sight line (LoS) [26]. In [27], the authors proposed max-min energy-efficient enhanced Inter-cell Interference Coordination (eICIC) configuration algorithm to study energy usage in combination with UDN interference coordination. The proposed algorithm shows users achieve performance and fairness for energy consumption. They also identified a new energy efficiency trade-off between macro user and small cell user with interference coordination in UDN. Furthermore, ultra-dense small cell network also can result in complex interference problem. To address this problem, research on [28] proposed multi-domain interference management scheme between collaborative small cells to minimize interference while improving the overall feasibility of the network. They used a distributed joint interference management (JIM) algorithm and as a result, each small cell base station can interact and self-organize to form combination and reduce the interference from multi-domain.

\subsection{Spectrum Scarcity}

Spectrum scarcity is another influence factor of the challenges in UDN. Spectrum sharing is one of the methods to provide efficient spectrum usage. The method of spectrum sharing is based on a low consumption channel in primary users where the secondary user can use the channel. However, there are new challenges for spectrum sharing in UDN. For instance, rising of traffic demand and interference in enterprise building. To overcome these, [29] suggested regulatory policies in areas of high demand, taking into account three regulatory policies relating to the regulation of regional control, the regulation of deployment locations and the combination of both. The deployment position control can therefore be the most effective to reduce interference with the radar system and improve sharing conditions. Another key method to tackle spectrum scarcity is by using graph theory which implements assignment of different colour to the adjacent vertexes for resource allocation and interference coordination. The authors in [30] suggested a Coloring-based Cluster Resource Allocation (CCRA) algorithm for large 
N. Mohd Nordin et al., International Journal of Advanced Trends in Computer Science and Engineering, 9(1.4), 2020,345 - 352

phantom cells to greatly boost spectrum efficiency and performance in UDN. First step in their scheme is to build a virtual network interference graph according to user input. Next Coloring algorithms are used for the vertexes and allocated to the phantom cluster. If users have the same virtual cluster, the frequency band can then be reused.

\subsection{Mobility Demands}

One of the problems in UDN is the vast amount of different terminal types and wide variety of facilities, and the accessibility demands. Mobility in mobile communication systems which is usually done by handover. Handover with the limited UDN coverage is expected to occur much more frequently. UE is exploring the signal quality and availability through cell discovery during the handover process. The optimum small cell serving is chosen based on calculation of the efficiency of the reference signal, signal-to-interference-plus-noise ratio (SINR). Authors in [31] proposed about UEs mobility in the small cell UDN where they use a novel adaptive per-UE cell clustering scheme based on UE mobility state estimation combined with a non-coherent Cooperative Multi Points (CoMP) Joint Transmission (JT). The size of the cell cluster is individually customized for each user, based on their mobility state. From this, network efficiency in terms of usability and throughput has improved. The rapid and adaptable implementation of small cell access points and backhaul networking is another solution to meeting mobility requirements. In [32], the authors proposed two important mechanisms for localized mobility control, small cell implementations and backhaul topology. The better output, based on the results, is decentralized mobility management with a centralized control system, while the other has less handover signalling costs with higher handover latency.

\subsection{Various QoS Demand}

The emerging demand for broadband Internet services such as online video streaming and audio streaming is increasingly growing. QoS therefore needs to cater for many new applications and their demands in the mobile network. QoS monitors and manages network resources by prioritization of EU requirements from different user perspective. Depending on the application type, QoS is given priority based on the delay, data rate, failure rate, jitter and other requirements. Many emerging applications, such as online video, e-health monitoring and intelligent transportation, require higher QoS specifications for ultra-high reliability, privacy and protection, etc. In order to overcome various QoS demand and improve the throughput of the whole network, Authors in [33] proposed transmission scheme for QoS-based cross-tier corporation over UDN. To minimize the cross-tier interference they have used the dedicated channel system and to increase the overall data rate of the network, the cross-tier cooperation is used. Their simulation results indicate that the suggested scheme is performing better than the schemes for non-cooperation (NC) and full cooperation (FC). Next, authors in [34] stated that for the application of QoS in 5G or UDN, which is high-speed video flow server-subscriber and massive machine to machine (M2M), two major factor traffic models should be handled.

\section{SYSTEM MODEL}

In this section, two types of performance study are done which cover the study of:

1) Effect of applications types with different types of scheduling services, and

2) Effect of increase number of users.

\subsection{System Model 1}

In this system model, the simulation consists of UEs with different types of applications as shown in Figure 1. The applications considered in this model are Constant Bit Rate (CBR), email, File Transfer Protocol (FTP), Hypertext Transfer Protocol (HTTP), video and voice. On the other hand, scheduling services used are Best Effort (BE), Unsolicited Grant Service (UGS), Real Time Polling Service (RTPS), Extended Real Time Polling Service (ERTPS) and Non Real Time Polling Service (NRTPS). Detailed description of these application and QoS class are listed in Table 1 and Table 2, respectively [35].

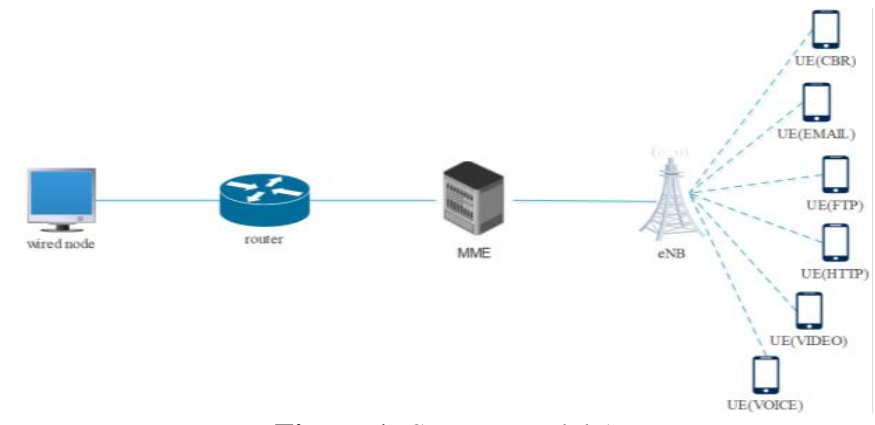

Figure 1: System Model 1

Table 1: Application Types [35]

\begin{tabular}{|l|l|}
\hline $\begin{array}{l}\text { Application } \\
\text { Types }\end{array}$ & \multicolumn{1}{c|}{ Description } \\
\hline $\begin{array}{l}\text { CBR - } \\
\text { Constant Bit } \\
\text { Rate }\end{array}$ & $\begin{array}{l}\text { Constantly sized packets are generated at } \\
\text { constant intervals. }\end{array}$ \\
\hline Email & $\begin{array}{l}\text { Enable users to send/receive email } \\
\text { application. }\end{array}$ \\
\hline $\begin{array}{l}\text { HTTP - } \\
\text { Hyper Text } \\
\text { Transfer } \\
\text { Protocol }\end{array}$ & $\begin{array}{l}\text { HTTP is a protocol for the transfer of data } \\
\text { among computers using TCP (users and web } \\
\text { servers as regular). }\end{array}$ \\
\hline
\end{tabular}


N. Mohd Nordin et al., International Journal of Advanced Trends in Computer Science and Engineering, 9(1.4), 2020,345 - 352

\begin{tabular}{|l|l|}
\hline $\begin{array}{l}\text { FTP - File } \\
\text { Transfer } \\
\text { Protocol }\end{array}$ & $\begin{array}{l}\text { This is a local network protocol for the } \\
\text { transition of data between server and user. }\end{array}$ \\
\hline Voice & $\begin{array}{l}\text { It lets users move from user to server voice } \\
\text { applications } \\
\text { (Allocation is unchanged for all types of } \\
\text { codec, except personalized) }\end{array}$ \\
\hline Video & $\begin{array}{l}\text { It helps users to configure client-server video } \\
\text { applications. }\end{array}$ \\
\hline
\end{tabular}

Table 2: QoS Class [35]

\begin{tabular}{|c|c|c|}
\hline QoS Class & Description & Priority \\
\hline $\begin{array}{l}\text { UGS } \\
\text { Unsolicited } \\
\text { Grant Service }\end{array}$ & $\begin{array}{l}\text { It is a sort of scheduling } \\
\text { service that helps uplink of } \\
\text { real time services that } \\
\text { periodically convey data } \\
\text { packets of a fixed size. }\end{array}$ & High \\
\hline $\begin{array}{l}\text { rtPS } \\
\text { Real-time } \\
\text { Polling } \\
\text { Service }\end{array}$ & $\begin{array}{l}\text { The rtPS scheduling service } \\
\text { type is designed to support } \\
\text { real-time data flows that } \\
\text { transport variable-sized data } \\
\text { packets on periodic basis. } \\
\text { For instance is video format } \\
\text { of MPEG (Moving Pictures } \\
\text { Experts Group). }\end{array}$ & Medium \\
\hline $\begin{array}{l}\text { ertPS } \\
\text { Extended } \\
\text { real-time } \\
\text { Polling } \\
\text { Service }\end{array}$ & $\begin{array}{l}\text { ertPS is a scheduling system } \\
\text { that maximizes the value of } \\
\text { UGS and rtPS effectiveness. } \\
\text { UGS distributions are fixed } \\
\text { in size whereas variable in } \\
\text { ertPS distributions. This QoS } \\
\text { class is suitable for variable } \\
\text { rate of real-time service } \\
\text { flows with bit rate and } \\
\text { demand for delays. }\end{array}$ & Normal \\
\hline $\begin{array}{l}\text { nrtPS } \\
\text { Non-real-time } \\
\text { Polling } \\
\text { Service }\end{array}$ & $\begin{array}{l}\text { It is used for data flow } \\
\text { without any guarantee of } \\
\text { delay during network traffic } \\
\text { consists of data packets of } \\
\text { variable size, but minimal } \\
\text { traffic rate is guaranteed like } \\
\text { FTP request. }\end{array}$ & Low \\
\hline $\begin{array}{l}\mathbf{B E} \\
\text { Best Effort }\end{array}$ & $\begin{array}{l}\text { The BE service provides } \\
\text { efficient applications where } \\
\text { no minimum service } \\
\text { guarantees are needed. }\end{array}$ & Low \\
\hline
\end{tabular}

\subsection{System Model 2}

The purpose of this system model is to study the effect of increasing number of users. The simulation of this model is done by two samples. First sample consists of a HNB Gateway, 4 HNBs, 4 UEs, a Router and a Wired Node as shown in Figure 2. While for the second sample, another 4 HNBs and 4 UEs are added in the simulation.

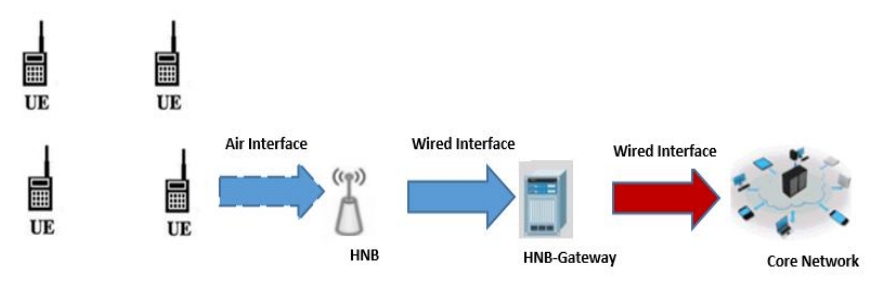

Figure 2: System Model 2

\section{SIMULATION RESULTS}

Simulation has been done by using NetSim software and the simulation results are analysed based on the performance of UEs in terms of packet delay and throughput.

\subsection{Applications Types on Different Types of Scheduling Services}

The performance measurement of the various service classes offered in the default was carried out by analyzing various QoS parameters including throughput and delay for different types of applications

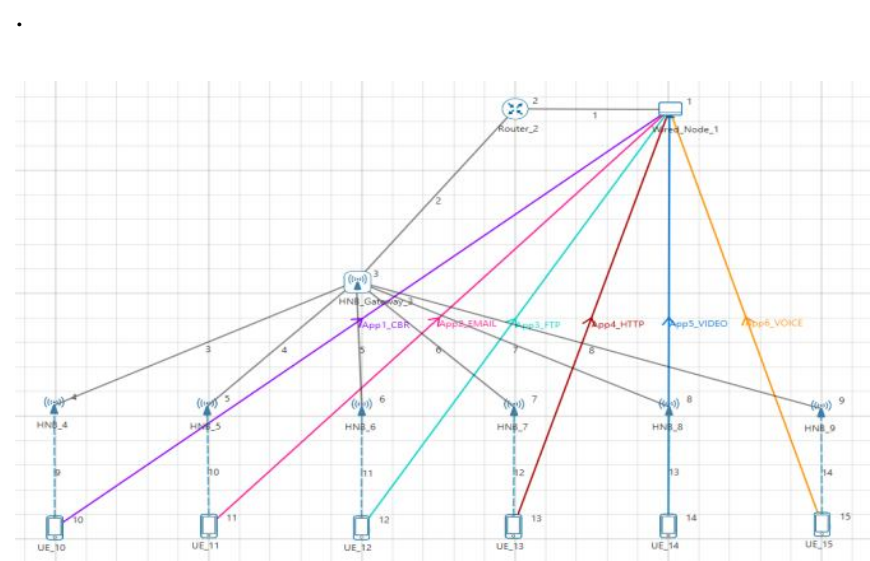

Figure 3: Simulation of Applications Types on Different Types of Scheduling Services

Simulation considered six UEs with different types of applications including CBR, email, FTP, HTTP, video and voice as shown in the Figure 3. Figure 4 shows that HTTP have two outputs; HTTP 1 and HTTP 2 are for sending and page loading, respectively. It is observed from the graph that the CBR application has the highest throughput for all forms of scheduling services. In QoS networks, CBR traffic is 
treated as high priority traffic. From all types of QoS, they all have the same throughput in all applications except for HTTP application in UGS service. This is because of occurrence of packet loss during data transmission.

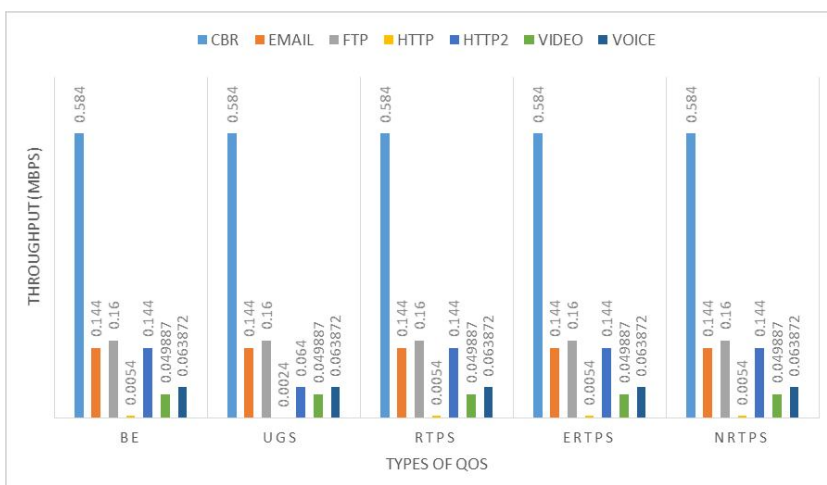

Figure 4: Graph of Throughput in Each Application with Different Types of Scheduling Services

Based on Figure 5, the results show that QoS of UGS has highest delay for all applications except for video and voice applications, as compared to other scheduling services. UGS is intended to serve uplink service flows in real time, which transmit standard fixed-size data packets like VoIP without silent suppression. Thereby, the QoS of UGS prioritizes video and voice applications with the minimum delay according to the Standardized QCI characteristics [36]. From all types of QoS, it can be concluded that the maximum delay obtained was FTP application due to the lowest priority level. From Figure 4 and Figure 5, it is observed that when the delay is increased the throughput is decreased.

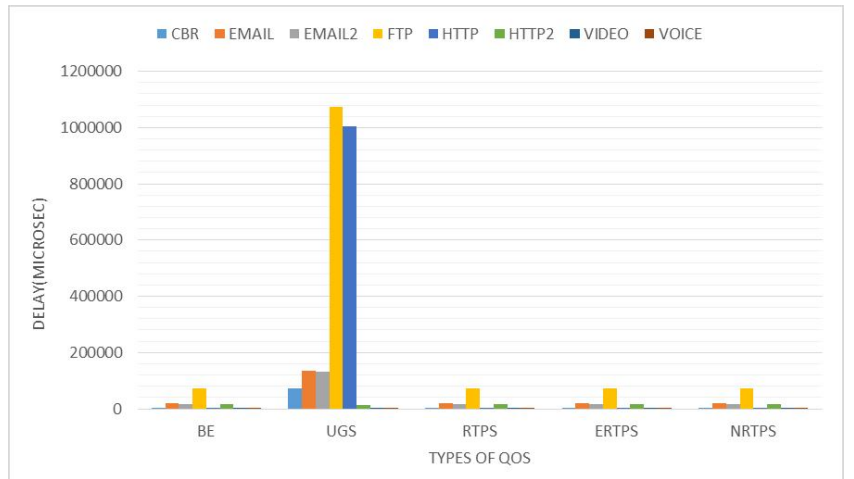

Figure 5: Graph of Delay in Each Application with Different Types of Scheduling Services

\subsection{The Performance of Increasing Number of UE in LTE Femtocell Technology}

In this simulation, the increasing numbers of UE in LTE femto cell technology are compared as shown in Figure 6 and Figure 7. We assumed that each HNB is serving only one UE.

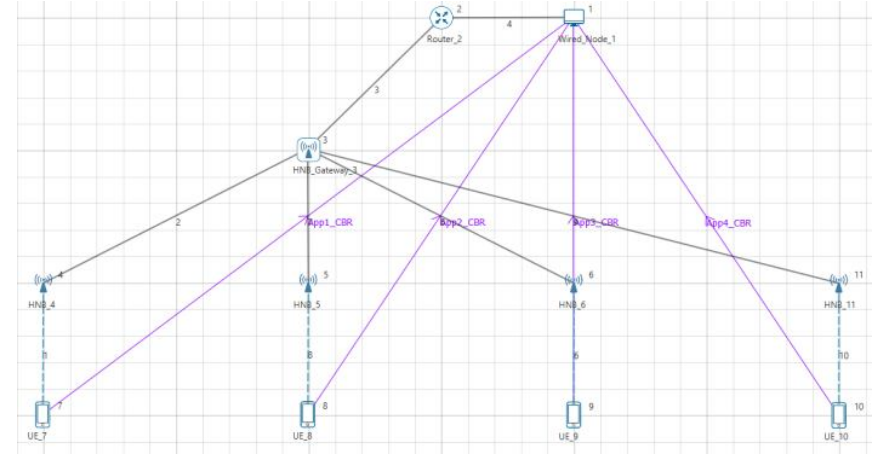

Figure 6: Simulation of UE with HNB

Table 3 shows the results of UE with HNB while Table 5 shows the results of more UEs are added with its serving HNB. It shows that as the UE with HNB is increased, the throughput is decreased due to the sharing of resource block. Whenever an additional HNB is connected to the HNB Gateway, it will have to coexist in one of the three available channels by sharing the frequency and resource blocks with the other HNBs operating in the same frequency. As shown in Table 4, allocation information for UE with HNB, we can see that all the HNBs shared resource blocks equally to each HNB which is the allocation of 52 resource blocks each. HNB 4 and HNB 5 coexist in the same channel $\mathrm{CH} 1$ in the frequency $2110-2140 \mathrm{MHz}$. While the other two HNBs, HNB 6 and HNB 11 occupied CH2 in the frequency 2140-2170 MHz. Table 6 shows that when more UEs are added, all the HNBs also shared the same resource blocks which is the allocation of 20 resource blocks each. HNB 4, HNB 5, HNB 16 and HNB 18 coexist in the same channel $\mathrm{CH} 1$ in the frequency 2110 $2140 \mathrm{MHz}$. For $\mathrm{CH} 2$ in the frequency $2140-2170 \mathrm{MHz}$, it is occupied by HNB 6, HNB 11, HNB 17 and HNBB 19.

\section{CONCLUSION}

In this paper, challenges of UDN with existence of femtocells are discussed. Simulation is done using NetSim. In system model 1, a study of different types of applications are tested with different types of scheduling services. It can be concluded that delay and throughput are affected by priority level of the applications. CBR application has highest throughput because of its high priority in QoS network. Then, video and voice applications have lowest delay in UGS achieved through their high priority in UGS. Then, system model 2 is simulated to study the effect of increase number of users. This simulation shows that the throughput is affected when new UEs are added due to the resource block sharing which indicates that spectrum reuse is needed, to accommodate more users. The frequency and resource blocks are shared with the other HNBs when an additional HNB is connected to the HNB Gateway and has to coexist in one of the three available channels. In future works, this study aims to implement frequency reuse to boost up network spectrum efficiency and overall throughput. 
N. Mohd Nordin et al., International Journal of Advanced Trends in Computer Science and Engineering, 9(1.4), 2020,345 - 352

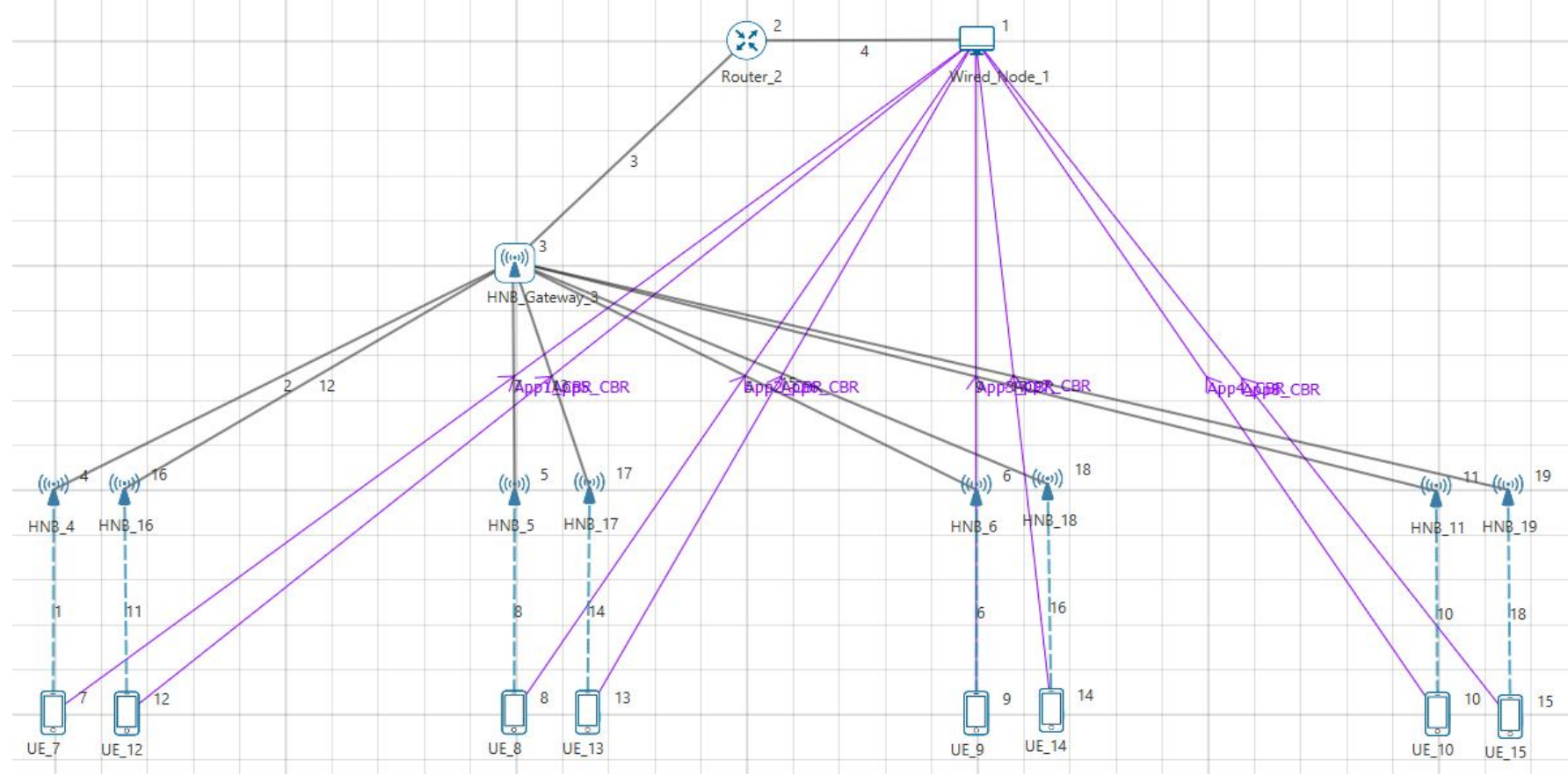

Figure 7: Simulation of More UE with the Newly Added HNB

Table 3: Result for UE with HNB

\begin{tabular}{|c|c|c|c|c|c|c|c|}
\hline $\begin{array}{c}\text { Application } \\
\text { Id }\end{array}$ & $\begin{array}{c}\text { Application } \\
\text { Name }\end{array}$ & $\begin{array}{c}\text { Source } \\
\text { Id }\end{array}$ & Destination & $\begin{array}{c}\text { Packet } \\
\text { generated }\end{array}$ & $\begin{array}{c}\text { Packet } \\
\text { received }\end{array}$ & $\begin{array}{c}\text { Throughput } \\
\text { (Mbps) }\end{array}$ & Delay (microsec) \\
\hline 1 & App1_CBR & 7 & 1 & 86207 & 9991 & 11.66949 & 4421944.356533 \\
\hline 2 & App2_CBR & 8 & 1 & 86207 & 9992 & 11.67066 & 4422120.641873 \\
\hline 3 & App3_CBR & 9 & 1 & 86207 & 9989 & 11.66715 & 4420418.349573 \\
\hline 4 & App4_CBR & 10 & 1 & 86207 & 9998 & 11.67766 & 4420335.547998 \\
\hline
\end{tabular}

Table 4: Allocation Information for UE with HNB

\begin{tabular}{|c|c|c|c|c|c|}
\hline HNB Id-CA Id & FMin (MHz) & FMax (MHz) & RBStart & RBEnd & RB allocation \\
\hline $4-0$ & 2110 & 2140 & 0 & 52 & 52 \\
\hline $6-0$ & 2140 & 2170 & 0 & 52 & 52 \\
\hline $5-0$ & 2110 & 2140 & 52 & 104 & 52 \\
\hline $11-0$ & 2140 & 2170 & 52 & 104 & 52 \\
\hline
\end{tabular}

Table 5: Results with Newly Added HNB and UEs

\begin{tabular}{|c|c|c|c|c|c|c|c|}
\hline $\begin{array}{c}\text { Application } \\
\text { Id }\end{array}$ & $\begin{array}{c}\text { Application } \\
\text { Name }\end{array}$ & Source Id & $\begin{array}{c}\text { Destination } \\
\text { Id }\end{array}$ & $\begin{array}{c}\text { Packet } \\
\text { generated }\end{array}$ & $\begin{array}{c}\text { Packet } \\
\text { received }\end{array}$ & $\begin{array}{c}\text { Throughput } \\
\text { (Mbps) }\end{array}$ & Delay(microsec) \\
\hline 1 & App1_CBR & 7 & 1 & 86207 & 2495 & 2.91416 & 4857183 \\
\hline 2 & App2_CBR & 8 & 1 & 86207 & 2491 & 2.909488 & 4863269 \\
\hline 3 & App3_CBR & 9 & 1 & 86207 & 2495 & 2.91416 & 4857678 \\
\hline 4 & App4_CBR & 10 & 1 & 86207 & 2498 & 2.917664 & 4857821 \\
\hline 5 & App5_CBR & 12 & 1 & 86207 & 2493 & 2.911824 & 4853531 \\
\hline 6 & App6_CBR & 13 & 1 & 86207 & 2491 & 2.909488 & 4859423 \\
\hline 7 & App7_CBR & 14 & 1 & 86207 & 2495 & 2.91416 & 4859238 \\
\hline 8 & App8_CBR & 15 & 1 & 86207 & 2493 & 2.911824 & 4857546 \\
\hline
\end{tabular}


N. Mohd Nordin et al., International Journal of Advanced Trends in Computer Science and Engineering, 9(1.4), 2020,345 - 352

Table 6: Allocation Information for Newly Added HNB and UEs

\begin{tabular}{|c|c|c|c|c|c|}
\hline HNB Id-CA Id & FMin (MHz) & FMax (MHz) & RBStart & RBEnd & RB allocation \\
\hline $4-0$ & 2110 & 2140 & 0 & 20 & 20 \\
\hline $6-0$ & 2140 & 2170 & 0 & 20 & 20 \\
\hline $5-0$ & 2110 & 2140 & 20 & 40 & 20 \\
\hline $11-0$ & 2140 & 2170 & 20 & 40 & 20 \\
\hline $16-0$ & 2110 & 2140 & 40 & 60 & 20 \\
\hline $17-0$ & 2140 & 2170 & 40 & 60 & 20 \\
\hline $18-0$ & 2110 & 2140 & 60 & 80 & 20 \\
\hline $19-0$ & 2140 & 2170 & 60 & 80 & \\
\hline
\end{tabular}

\section{ACKNOWLEDGEMENT}

This work was supported by Ministry of Higher Education (MOHE), Faculty of Engineering Technology, Research Management Centre, Universiti Tun Hussein Onn Malaysia (UTHM) under Fundamental Research Grant Scheme (FRGS) (Vote No: 1647).

\section{REFERENCES}

1. M. Abata, M. Fattah, S. Mazer, M. Mehdi, and M. E. L. Bekkali, "Study and Design of a MMIC Voltage Controlled Oscillator for 5G mm-wave band Applications," Int. J. Adv. Trends Comput. Sci. Eng., vol. 9, no. 2, pp. 2124-2129, 2020. https://doi.org/10.30534/ijatcse/2020/186922020

2. M. Amin Salih Mohammed, Daroon Mudhafar Hamad, M.Sivaram, V.Porkodi, "Analysis of Mobile IP Wireless Networks in 5G," Int. J. Adv. Trends Comput. Sci. Eng., vol. 8, no. 1.2, pp. 39-42, 2019.

3. P. Pirinen, "A Brief Overview of $5 \mathrm{G}$ Research Activities," Proc. 1st Int. Conf. 5G Ubiquitous Connect., vol. 5, no. December, 2014.

4. I. Hwang, B. Song, and S. Soliman, "A holistic view on hyper-dense heterogeneous and small cell networks," IEEE Commun. Mag., vol. 51, no. 6, pp. 20-27, June 2013.

5. Fehske, A. J., Viering, I., Voigt, J., Sartori, C., Redana, S., \& Fettweis, G. P. (2014). Small-cell self-organizing wireless networks. Proceedings of the IEEE, 102(3), 334-350.

6. A. Osseiran et.al, "Scenarios for 5G mobile and wireless communications: the vision of the METIS project, " IEEE Communi. Mag. , vol.52, no.5, pp.26--35, May 2014.

7. 3GPP TR 25.814, "Physical Layer Aspects for Evolved UTRA (Release 7)", May 2006.

8. Y. Li and Z. Feng, "Enterprise Femtocell Network Optimization based on Neural Network Modeling," 2011 IEEE Consum. Commun. Netw. Conf., no. 60632030, pp. 1130-1131, 2011.

9. Talha Zahir, Kamran Arshad, Atsushi Nakata, and Klaus Moessner, "Interference Management in Femtocells,"
Communications Surveys \&Tutorials, IEEE, vol. PP, no. 99, pp. 1-19, 2012.

10. David Lpez-Prez, Alvaro Valcarce, and Guillaume de la Roche, "OFDMA Femtocells: A Roadmap on Interference Avoidance," IEEE Communications Magazine, vol.47, no.9, pp.41-48, September 2009.

11. W. Yi, Z. Dongmei, J. Hai, and W. Ye, "A Novel Spectrum Arrangement Scheme for Femtocell Deployment in LTE Macrocells," Proc. IEEE $20^{\text {th }}$ Symposium on Personal, Indoor and Mobile Radio Communications, pp. 6-11, 13-16 Sept. 2009.

12. J. Xiang, Y. Zhang, and T. Skeie, L. Xie, "Downlink Spectrum Sharing for Cognitive Radio Femtocell Networks," IEEE Systems Journal, vol.4, no.4, pp.524-534, Dec. 2010. https://doi.org/10.1109/JSYST.2010.2083230

13. Chee Wei Tan, "Optimal power control in Rayleigh-fading heterogeneous networks," INFOCOM, 2011 Proceedings IEEE, vol., no., pp.2552-2560, 10-15 April 2011.

14. Zahir, Talha, et al. "Interference management in femtocells".

15. López-Pérez, David, et al. "OFDMA femtocells: a roadmap on interference avoidance." Communications Magazine, IEEE 47.9 (2009): 41-48.

16. M. Kamel, W. Hamouda, and A. Youssef, "Ultra-Dense Networks: A Survey," IEEE Communications Surveys \& Tutorials, vol. 18, no. 4, pp. 2522-2545, 2016.

17. Nokia, "Ultra dense network (UDN) white paper," in Nokia Solutions and Neworks Oy, 2016.

18. D.Gonz'alez Gonz'alez, E. Mutafungwa,B.Haile, J.H"am"al"ainen, and H. Poveda, "A Planning and Optimization Framework for Ultra Dense Cellular Deployments," Mobile Information Systems, vol. 2017, 2017.

19. Y. Wei and S.-H. Hwang, "Optimization of Cell Size in Ultra-Dense Networks with Multiattribute User Types and Different Frequency Bands," Wirel. Commun. Mob. Comput., vol. 2018, pp. 1-10, 2018.

20. K. Wang, Y. Wang, Y. Sun, S. Guo, and J. Wu, "Green industrial Internet of Things architecture: An energy-efficient perspective," IEEE Commun. Mag., vol. 54, no. 12, pp. 48-54, Dec. 2016. 
N. Mohd Nordin et al., International Journal of Advanced Trends in Computer Science and Engineering, 9(1.4), 2020,345 - 352

21. S. Fu, H. Wen, J. Wu, and B. Wu, "Cross-networks energy efficiency tradeoff: From wired networks to wireless networks," IEEE Access, vol. 5, pp. 15-26, 2017.

22. J. Wu, S. Guo, J. Li, and D. Zeng, "Big data meet green challenges: Greening big data," IEEE Syst. J., vol. 10, no. 3, pp. 873-887, Sep. 2016.

23. FW. Yu, H. Xu, H. Zhang, D. Griffith, and N. Golmie, "Ultra-Dense Networks: Survey of State of the Art and Future Directions," 2016 25th Int. Conf. Comput. Commun. Networks, ICCCN 2016, 2016.

24. I. Viering, M. Peltomäki, O. Tirkkonen, M. Alava, and R. Waldhauser. A distributed power saving algorithm for cellular networks. In Self-Organizing Systems, pages 232-237. Springer, 2009.

25. Yuyi Mao et al., "Energy Harvesting Small Cell Networks: Feasibility, Deployment, and Operation", IEEE Commun. Mag., vol. 53, no. 6, June 2015, pp. 94-101.

26. Y. Teng, M. Liu, F. R. Yu, V. C. M. Leung, M. Song, and Y. Zhang, Resource Allocation for Ultra-Dense Networks: A Survey, Some Research Issues and Challenges, vol. 21, no. 3. IEEE, 2019. https://doi.org/10.1109/COMST.2018.2867268

27. J. I. E. Zheng, L. Gao, H. Zhang, S. Member, and D. Zhu, "Joint Energy Management and Interference Coordination With Max-Min Fairness in Ultra-Dense HetNets," IEEE Access, vol. 6, pp. 32588-32600, 2018.

28. S. N. A. Multi-domain, "Joint Interference Management in Ultra-Dense Coordination Perspective," IEEE Trans. Commun., vol. 66, no. 11, pp. 5470-5481, 2018.

29. E. Obregon, K. W. Sung, and J. Zander. On the sharing opportunities for ultra-dense networks in the radar bands. In Proc. of 2014 IEEE International Symposium on Dynamic Spectrum Access Networks (DYSPAN), 2014.

30. C. Zhao, X. Xu, Z. Gao, and L. Huang, "A Coloring-based Cluster Resource Allocation for Ultra Dense Network," 2016 IEEE Int. Conf. Signal Process. Commun. Comput., pp. 1-5, 2016.

31. M. Joud, M. Garc, and S. Ruiz, "User Specific Cell Clustering to Improve Mobility Robustness in 5G Ultra-dense Cellular Networks," pp. 45-50, 2018.

32. H. Wang, S. Chen, S. Member, M. Ai, and H. Xu, "Localized Mobility Management for 5G Ultra Dense Network," vol. 66, no. 9, pp. 8535-8552, 2017.

33. J. Peng, J. Zeng, X. Su, B. Liu, and H. Zhao, "A QoS-Based Cross-Tier Cooperation Resource Allocation Scheme Over Ultra-Dense HetNets," IEEE Access, vol. 7, pp. 27086-27096, 2019. https://doi.org/10.1109/ACCESS.2019.2901506

34. M. Amin Salih Mohammed, Daroon Mudhafar Hamad, M.Sivaram, V.Porkodi, "Analysis of Mobile IP Wireless Networks in 5G," Int. J. Adv. Trends Comput. Sci. Eng., vol. 8, no. 1.2, pp. 39-42, 2019

35. T. Libraries and G. Started, "NetSim User Manual," ver. 11.1, pp. 1-244, 2019.
36. 3GPP. (2012).TS 23.203 Technical Specification Group Services and System Aspects; Policy and charging control architecture. 